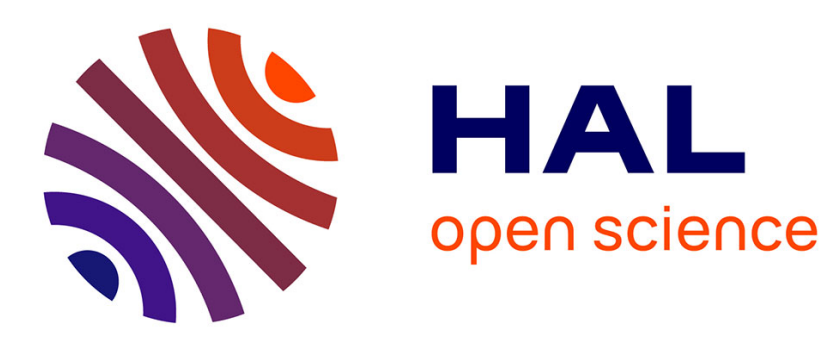

\title{
Influence of hygromechanical history on the longitudinal mechanosorptive creep of wood
}

Cédric Montero, Joseph Gril, Clémentine Legeas, David G. Hunt, Bruno Clair

\section{To cite this version:}

Cédric Montero, Joseph Gril, Clémentine Legeas, David G. Hunt, Bruno Clair. Influence of hygromechanical history on the longitudinal mechanosorptive creep of wood. Holzforschung, 2012, 66, pp.757-764. 10.1515/hf-2011-0174 . hal-00672336

\section{HAL Id: hal-00672336 https://hal.science/hal-00672336}

Submitted on 21 Feb 2012

HAL is a multi-disciplinary open access archive for the deposit and dissemination of scientific research documents, whether they are published or not. The documents may come from teaching and research institutions in France or abroad, or from public or private research centers.
L'archive ouverte pluridisciplinaire HAL, est destinée au dépôt et à la diffusion de documents scientifiques de niveau recherche, publiés ou non, émanant des établissements d'enseignement et de recherche français ou étrangers, des laboratoires publics ou privés. 
Title:

\title{
Influence of hygromechanical history on the longitudinal mechanosorptive creep of wood
}

\author{
Cédric Montero $^{1 *}$, Joseph Gril ${ }^{1}$, Clémentine Legeas ${ }^{1}$, David G. Hunt ${ }^{2}$, Bruno Clair ${ }^{1}$ \\ ${ }^{1}$ Laboratoire de Mécanique et Génie Civil (LMGC), Université Montpellier 2, CNRS, France \\ ${ }^{2}$ School of Construction Management and Engineering, Reading University, United Kingdom \\ *Corresponding author: cedric.montero@univ-montp2.fr
}

\begin{abstract}
An experiment was performed on Norway spruce to simplify our understanding of mechanosorptive creep. Two well-matched sets of specimens were subjected to the same humidity history but loaded in four-point bending at different times. One set was loaded dry, and thus experienced a considerable creep at first adsorption (the so-called ++ effect). The other set was then loaded wet and only exhibited, together with the dry-loaded set, the usual pattern of creep increase during drying (- effect) followed by a partial recovery during remoistening ( + effect). Both sets converged to the same response after a few cycles. The results confirm that a single type of mechanosorption, combined with strain-dependent hygroexpansion and humidity-dependent viscoelascity, is sufficient to account for all observed features of longitudinal creep of wood at ambient temperature.
\end{abstract}

Keywords: clear wood; creep; mechanosorption; moisture content

\section{Introduction}

During the lifetime of a timber structure, wood is subjected to continuous changes of humidity. Like other polymeric and hygroscopic materials, loaded wood creeps with time and the amount of creep is higher under the more humid conditions. Moreover, as evidenced by Armstrong and Kingston (1960), the adsorption-desorption process, associated with local variations of moisture content (MC) may advance the creep considerably. This particular feature of wood material, a coupling between mechanical response of wood and adsorption-desorption processes (Armstrong and Christensen 1961; Armstrong and Kingston 1962) was named mechanosorptive effect by Grossman (1976). It was given various physical interpretations (Boyd 1982; Back et al. 1983; Mukudai 1983; Bazant 1985; Hoffmeyer 1989; Navi and Stanzl-Tschegg 2009) although to date no clear consensus was reached.

It was found that during a bending test in changing humidity, the first increase of MC and any decrease cause an increase in deflection, whereas subsequent adsorption in the same MC range produces little creep or some recovery. According to these statements, the first adsorption of water has a special influence on the deflection. A first approach to the quantification of mechanosorptive creep was made by Ranta-Maunus (1975) based on plywood creep data. This author defined "hygroviscoelastic constants" to model the evolution of elastic compliance $J$ induced by change of MC. Three notations were proposed to designate the derivative of $J$ with respect to MC during first adsorption to a higher MC than has been experienced since the start of loading $a^{++}$, any desorption $a^{-}$, or subsequent adsorption within the MC range already experienced $a^{+}$(Figure 1a). 


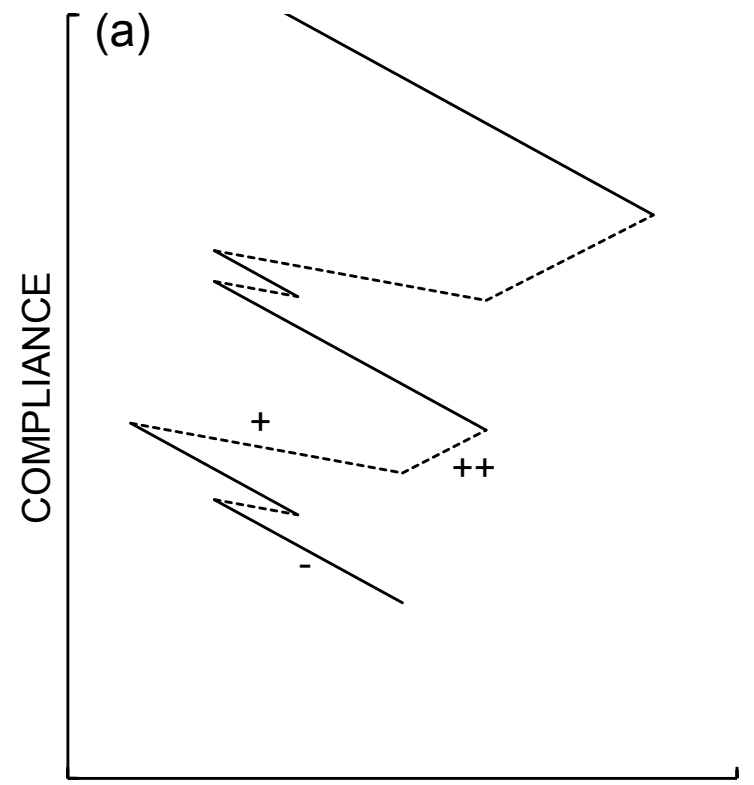

MOISTURE CONTENT

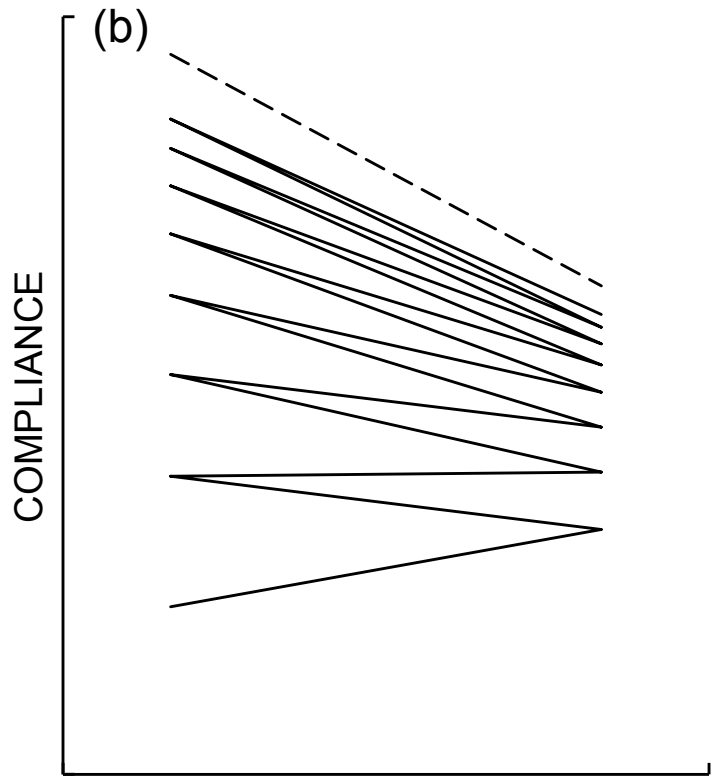

MOISTURE CONTENT

Figure 1: Hypothetical plots of compliance against moisture content

(a) with constant values of $\mathrm{a}^{++}, \mathrm{a}^{+}$and $\mathrm{a}^{-}$(humidifying ---, dehumidifying - - ) (from Hunt 1984) and (b) toward a creep limit with strain dependency of hydroviscoelastic constant (from Hunt 1989)

Later, Hunt (1984) observed that the values of these constants depend on strain and he proposed a limit to the amount of mechanosorptive creep, approached asymptotically by repeated humidity cycles. Hunt and Shelton (1987) proposed a simple procedure, based on overloading followed by one humidity cycle, to obtain rapidly the creep limit. The authors showed evidence of an asymptotic trend of decreasing compliance with increasing $\mathrm{MC}$, and described the compliance increase during drying as "pseudo-creep" and the decrease during humidifying as "pseudorecovery" (Figure 1b). They interpreted this phenomenon as a stress-dependent (or straindependent) coefficient of moisture expansion. A practical consequence of this finding was to allow desorption (- effect) and adsorption ( + effect) to be considered as equally contributing to mechanosorption, which simplified greatly the numerical models that were proposed later (Martensson 1988; Salin 1992; Mohager and Toratti 1993; Hanhijärvi 1995). According to these models, the mechanosorptive strain depends on the sum of the absolute value of MC increments, the "cumulative moisture content change". Experimental results in longitudinal tension (Muszyński et al. 2006) confirmed the applicability of this assumption to describe the creep response to a succession of humidity cycles under a constant tensile load, thanks to the fitting of the mechanosorptive strains to a single exponential curve. As the test started with a humidification period, these data suggested that the first wetting did not contribute differently from subsequent swelling, which thus contradicts the existence of a ++ effect. Already in 1984, Hunt suggested that a part of the strong increase of creep when "the maximum humidity since loading" is exceeded was caused by the normal increase of the viscoelastic compliance with humidity. Such analysis relies strongly on the possibility to separate a mechanosorptive contribution from the total strain. Hanhijärvi and Hunt (1998) tried to elucidate the interaction between viscoelastic creep (at constant humidity) and mechanosorptive creep (resulting from MC changes). Although they did observe an interaction based on the analysis of the kinetics, their procedure did not allow to conclude about the existence of the ++ effect because they loaded their specimen in the wet state so they only involved the "usual" type of mechanosorption.

The results presented in this paper are aiming at answering the question of the existence or non-existence of the ++ effect when wood creeps along the fibres. For that purpose, it is necessary to compare the mechanosorptive creep of wood submitted to humidity increase after being loaded dry, with that of wood directly loaded wet. In the first case, ++ effect is expected to occur while in the second, it is not. After this initial difference, both specimens should experience the same hygromechanical loading so that their final response can be compared. Bending was preferred to 
tensile load in this work in order to ensure no experimental artefacts even if the interpretation of a bending test is tricky especially in transient adsorption-desorption phases, as pointed out by Muszyński et al. (2006), and so special precautions were taken.

\section{Materials and method \\ Wood material}

Clear Norway spruce specimens were selected. Specimen size: $100 \mathrm{~mm}$ (long.) x $10 \mathrm{~mm}$ (rad.) x $2 \mathrm{~mm}$ (tang.) (Figure 2a). The ring width was $2.3 \mathrm{~mm}$, so that the cross-section contained about 4 rings loaded in parallel.
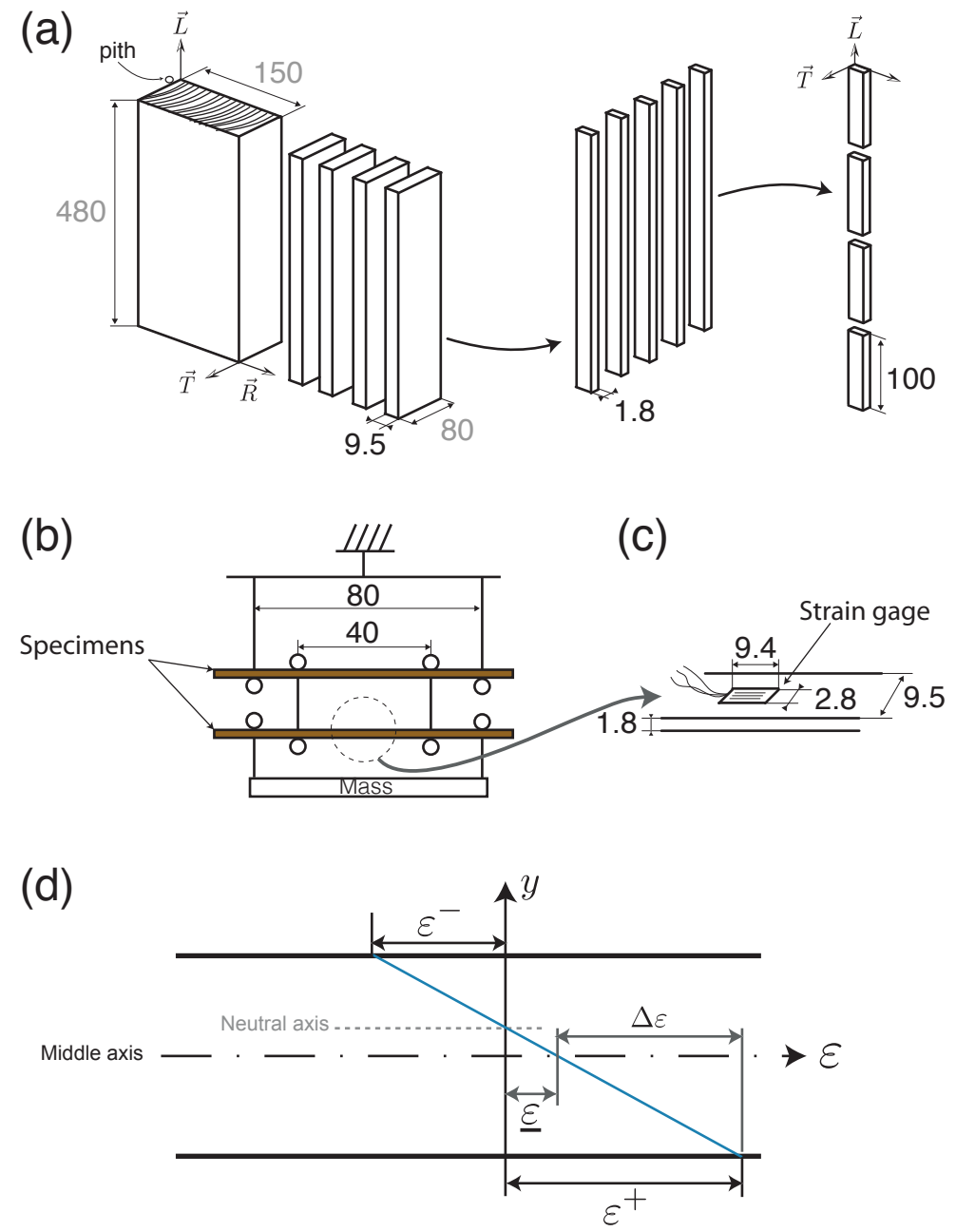

Figure 2: Log extraction and specimens orientation within the $\log$ (a). Experimental equipment of 4 point bending in serial arrangement (b) and gage dimensions (c). Scheme of strain field along specimen thickness (d) with indication of strain gauges measurements $\varepsilon^{+}$and $\varepsilon^{-}$, the mean strain $\underline{\varepsilon}$ and the differential strain $\Delta \varepsilon$

\section{Specimen selection}

A total of 18 specimens paired in two sets were required for this test. As the objective of the study was to compare 2 groups, a careful matching was necessary. 80 specimens were cut and their structural, hygroscopic and mechanical properties were measured by various non-destructive methods (Table 1). Average microfibril angle (MFA) and grain angle at 2 positions per specimen were determined by X-ray diffraction. The MFA was calculated according to the calibration of Yamamoto et al. (1993) and the grain angle with the methodology described in Brémaud (2011). The specific modulus and damping coefficient were measured under free-free vibration conditions (Brémaud 2006). Dimensional changes from 70 to $92 \%$ RH and from 92 to 50\% RH were measured in the tangential direction with a calliper. 
Table 1: Variability of specimen properties characterized using various non destructive methods

\begin{tabular}{|c|c|c|c|}
\hline Property & Min & $\operatorname{Max}$ & Mean ( \pm St.D) \\
\hline Mean fibril angle $^{(1)}\left({ }^{\circ}\right)$ & 9 & 17 & $13(2)$ \\
\hline Grain angle $^{(1)}\left({ }^{\circ}\right)$ & 0.0 & 2.4 & $0.6(0.5)$ \\
\hline Density ${ }^{(2)}\left(\mathrm{g} \mathrm{cm}^{-3}\right)$ & 0.397 & 0.532 & $0.429(0.016)$ \\
\hline Specific modulus $^{(2)}(\mathrm{GPa})$ & 24.9 & 31.0 & $28.1(1.6)$ \\
\hline & 5.6 & 8.8 & $6.7(0.6)$ \\
\hline$\alpha_{T 70-92 \% \mathrm{RH}^{(3)}}(\% / \%)$ & 0.330 & 0.472 & $0.387(0.032)$ \\
\hline$\alpha_{T} 92-50 \% \mathrm{RH}^{(3)}(\% / \%)$ & 0.289 & 0.516 & $0.410(0.042)$ \\
\hline
\end{tabular}

(1) X-ray diffraction ${ }^{(2)}$ estimation from vibrational properties at $\mathrm{T}=22{ }^{\circ} \mathrm{C}, 44 \% \mathrm{RH},{ }^{(3)}$ hygroscopic coefficient in tangential direction for swelling (from 70 to $92 \% \mathrm{RH}, \mathrm{T}=20^{\circ} \mathrm{C}$ ) and shrinkage (from 92 to $\left.50 \% \mathrm{RH}, \mathrm{T}=20^{\circ} \mathrm{C}\right)$.

Previous experiments have shown that a close positioning of the specimen within the original log is not sufficient to ensure correct matching. The MFA is presented for information but was not used to select specimens because the measurement performed was clearly affected by the position of the X-ray beam, both in earlywood and latewood, where MFA differs (Herman et al., 1999). To guarantee a good matching between the two groups, a selection procedure by specimen pairing was developed. A first selection of 55 specimens was done to remove specimens with local disturbances of grain angle or inappropriate dimensions. The selection was made in order to minimize, for each property, the difference of average and standard deviation (StD) between both sets. The values of each set for each measured property are listed in Table 2 . The small difference in average and StD of specimen properties between each group attests the quality of the matching.

Table 2: Variability of each set of specimens using results of non destructive methods after specimen selection ( 9 specimens per set). For explanations see also Table 1.

\begin{tabular}{lcccccc}
\hline \multirow{2}{*}{ Property } & \multicolumn{3}{c}{ Dry-loaded set } & \multicolumn{3}{c}{ Wet-loaded set } \\
\cline { 2 - 7 } & Min & Max & Mean $( \pm \mathrm{StD})$ & Min & Max & Mean $( \pm \mathrm{StD})$ \\
\hline Density & 0.395 & 0.450 & $0.421(0.020)$ & 0.394 & 0.441 & $0.423(0.015)$ \\
Specific modulus ${ }^{(2)}(\mathrm{GPa})$ & 27.3 & 29.8 & $28.8(1.0)$ & 27.4 & 31.1 & $29.4(1.3)$ \\
$\tan \delta_{\mathrm{L}}^{\left({ }^{(2)}(\% \%)\right.}$ & 6.1 & 7.1 & $6.4(0.4)$ & 5.9 & 6.7 & $6.2(0.3)$ \\
$\alpha_{\mathrm{T} 70-92 \% \mathrm{RH}^{(3)}(\% / \%)}^{(3)}(\% / \%)$ & 0.363 & 0.455 & $0.406(0.036)$ & 0.362 & 0.452 & $0.407(0.034)$ \\
$\alpha_{\left.\mathrm{T} 92-50 \% \mathrm{RH}^{(}\right)}$ & 0.336 & 0.405 & $0.372(0.025)$ & 0.330 & 0.401 & $0.370(0.024)$ \\
Stress $\sigma^{0}(\mathrm{MPa})^{*}$ & 4.85 & 5.14 & $4.98(0.13)$ & 4.81 & 5.15 & $5.01(0.12)$ \\
\hline * applied with lead masses & & & & & &
\end{tabular}

* applied with lead masses

\section{Creep equipment and measurements}

Four-point bending devices with $40 \mathrm{~mm}$ inner span and $80 \mathrm{~mm}$ outer span were used. A serial arrangement with a pair of 2 specimens was designed to increase the repeatability in the same environmental conditions (Figure 2b).

Two groups of 6 specimens (labelled "dry-loaded set" and "wet-loaded set") and one group of 2 specimens per set (labelled "unloaded set") were placed in a controlled environment produced by a regulated climatic chamber $\left(\mathrm{T} \pm 0.35^{\circ} \mathrm{C}, \mathrm{RH} \pm 2 \%\right)$. On each of these specimens, the strain $\varepsilon^{+}$ was measured on the tensile face and $\varepsilon^{-}$on the compression face by means of strain gages with 3 wires and $5 \mathrm{~mm}$ grid length (KYOWA KFG-5-120-C1-11-L1M3R), fixed by gluing (Superglue Loctite Cyanoacrylate), and plugged into a data logger (two TML TDS-102-2) (figure 2c). One gage-less specimen per set was weighed occasionally to check any balance drift and to measure their transverse dimensions for the calculation of stress corrections. These operations were performed through a $5 \mathrm{~cm}$ diameter side opening and thus induced negligible perturbation of the climate of the chamber. The dimensions of the gauge support was $9.4 \times 2.8 \mathrm{~mm}$, so that in early transient phases of humidity changes, the perturbation due to the humidity barrier imposed by the gauge occurred at most on $1 / 3$ of the specimen width. 


\section{Hygromechanical history}

All creep results presented were measured in the longitudinal direction, and the experiments were performed at constant temperature $\mathrm{T}=23^{\circ} \mathrm{C} \pm 0.35^{\circ} \mathrm{C}$. The total duration of the test was 72 days. A preliminary acclimatizing phase of around $215 \mathrm{~h}$ without loading of the specimens was applied to release macroscopic residual strains. After this phase, the specimens of the dry-loaded set were loaded in the dry state $(\sim 10.4 \% \mathrm{MC})$. After a $5 \mathrm{~h}$ period of dry creep, the specimens were subjected to a humidity increase up to the maximum value allowed by the climatic chamber $(92 \% \mathrm{RH})$ to experience the "++" situation. This increase has been performed with slow RH variation (from $40 \% \mathrm{RH}$ to $92 \% \mathrm{RH}$ in $12 \mathrm{~h}$, ie $4 \% \mathrm{RH} / \mathrm{h}$ ) to avoid a high $\mathrm{MC}$ gradient within the specimen. After this increase, the dry-loaded set was subjected to wet creep $(92 \% \mathrm{RH})$ during $7 \mathrm{~h}$. The second group of specimens from the wet-loaded set, located in the same chamber, was then loaded wet $(\sim 19 \% \mathrm{MC})$ and subjected during 11 days to viscoelastic creep only. From that time, both specimens underwent creep at high humidity ( 19\% MC) punctuated by drying and moistening cycles of total duration of 1 day each (at the rate of $4 \% \mathrm{RH} / \mathrm{h}$ ). After 63 days of loading, both groups were unloaded and the recovery in the wet state was recorded.

The force was applied manually within $30 \mathrm{~s}$ with a lead mass designed to produce within the inner span a maximum stress $\sigma$ of about $5 \mathrm{MPa}$ under wet conditions (Table 2). Bending tests up to failure performed under similar conditions in an air dry environment with two matched specimens, allowed evaluation of the stress level as $6 \%$ of the failing load, well below the observed elastic limit of $60 \%$, although the non-linearity of mechanosorptive behaviour in bending was found to start at about $10-20 \%$ of the ultimate stress (Hunt 1989).

\section{Mechanical analysis}

The interpretation of bending tests requires special precautions especially during transient adsorption-desorption conditions where the non-homogeneity of stress distribution interacts in a complex manner with that of moisture. The use of a pair of strain gages instead of a measure of deflection allows, to some extent, to counterbalance the drawbacks of bending as a method for observing the intrinsic behaviour of the material. As the specimens were loaded at low stress level, we assume the applicability of the Bernouilli hypothesis. The strain field through the thickness can be calculated by linear interpolation between $\varepsilon^{+}$and $\varepsilon^{-}$:

$$
\varepsilon(y)=\underline{\varepsilon}+\Delta \varepsilon \cdot y
$$

where $\underline{\varepsilon}=\left(\varepsilon^{+}+\varepsilon^{-}\right) / 2$ and $\Delta \varepsilon=\left(\varepsilon^{+}-\varepsilon^{-}\right) / 2$ are the mean and differential strain, respectively, and $\mathrm{y}$ is the position along thickness relative to neutral axis (Figure $2 \mathrm{~d}$ ). The mean strain $\underline{\varepsilon}$ reveals stress independent phenomena occurring during adsorption-desorption such as the hygrothermal expansion (swelling and shrinkage), but also allows to check the linearity of the mechanical response, especially differences between compression and tension. The differential strain $\Delta \varepsilon$, half of the difference of strain between the two faces, is proportional to sample curvature. It mostly results from the action of the bending moment but can be also produced by differences of hygrothermal expansion between the tensile and compressive faces (causing pseudo creep/recovery, Figure 1b).

The stress is estimated by assuming a linear stress distribution through the thickness and refers to the maximum stress within the inner span. This is only a rough estimate during transient adsorption-desorption conditions, where the rigidity of the material and the strain distribution is heterogeneous. This difficulty exists for any loading mode but is exacerbated in bending due to the dominant contribution of the upper and lower faces. In equilibrium conditions, the validity of this estimate relies on the linearity of the mechanical response.

The effect of the change of transverse dimensions according to $\mathrm{MC}$ was considered in the stress determination, by means of the following equation: 


$$
\sigma=\frac{\sigma^{0}}{1+\alpha_{T}\left(w-w^{0}\right)}
$$

where $\alpha_{T}$ is the moisture expansion coefficient measured on an unloaded specimen $\left(\alpha_{T}=0.375 \% / \%\right), w$ is the mean MC of the specimen and $\sigma^{0}, w^{0}$ refer to the air-dry condition $\left(w^{0}=11 \% \mathrm{MC}\right)$. This corrected stress can be referred to as the "nominal stress", by analogy with the situation of a tensile mechanosorptive creep test, where a constant load is applied on a varying cross-section. In such case, no correction would be required as the water causing the transverse expansion is not supposed to contribute to the rigidity. Equation (2) takes into account the additional lever arm effect resulting from the application of a bending moment.

\section{Moisture content estimation}

The moisture content evolution was estimated based on the average of mean strain $\underline{\varepsilon}$ of loaded specimens, revealing the swelling and shrinkage of specimen. For that purpose, two specimens per set were placed in similar creep devices to those of the loaded specimens but were not loaded during the test and one specimen per set was gauge-less and weighed occasionally. Loading at this stress level did not influence significantly the hygroscopic behaviour of the specimens (Figure 3a). Due to the slow RH changes imposed on the wood, the MC did not deviate substantially from an equilibrium value. The evolution of $\mathrm{MC}$ was described by a third order polynomial function between the average of mean strain of all loaded specimens and occasional MC measurements (Figure $3 b)$. The rather high values of $\mathrm{MC}$ in the driest condition ( $40 \%$ R.H.) can be explained by the fact that the wood was never oven dried before the test (Kollmann and Côté 1968).
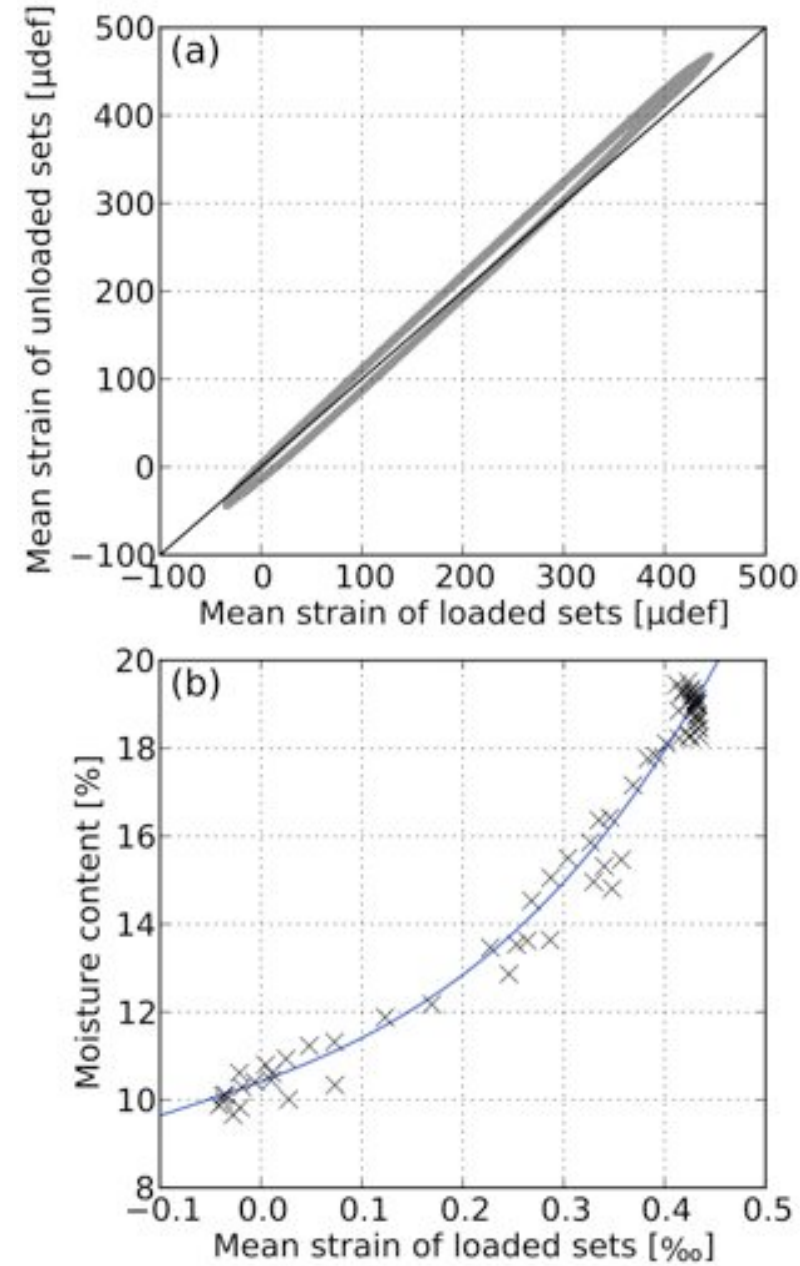

Figure 3: (a) Comparison of mean strain of loaded and unloaded specimens. (b) Determination of specimens MC. based on mean strain of loaded specimens at occasional MC measurements $X$ with the relation $\mathrm{w}=\mathrm{a} \underline{\varepsilon}^{3}+\mathrm{b} \underline{\varepsilon}^{2}+\mathrm{c} \underline{\varepsilon}+\mathrm{d}$ (with $\mathrm{a}=38.22, \mathrm{~b}=10.68, \mathrm{c}=8.45, \mathrm{~d}=10.42$ and $\underline{\varepsilon}$ in \%o) 


\section{Results}

\section{Experimental and analysed results}

Figure 4 gives an overview of the experimental data of this study. The complete hygrothermal history is shown in Figure 4a. A constant force was applied first to the dry-loaded set at $\mathrm{t}=215 \mathrm{~h}$ and then to the wet-loaded set at $\mathrm{t}=239 \mathrm{~h}$ (Figure $4 \mathrm{~b}$ ). As the dry-loaded set was loaded earlier, its value of differential strain $\Delta \varepsilon(\mathrm{t})$ remains above that of the wet-loaded set (Figure 4c) even if a part of the gap was already visible before loading, due to a small humidity-induced curvature of the specimens $\left(\Delta \varepsilon_{d r y}^{0}=-2 \mu \varepsilon\right.$ and $\left.\Delta \varepsilon_{w e t}^{0}=-16 \mu \varepsilon\right)$. This artefact can be explained by minor misalignments of strain gages and/or of fibres for each specimen.
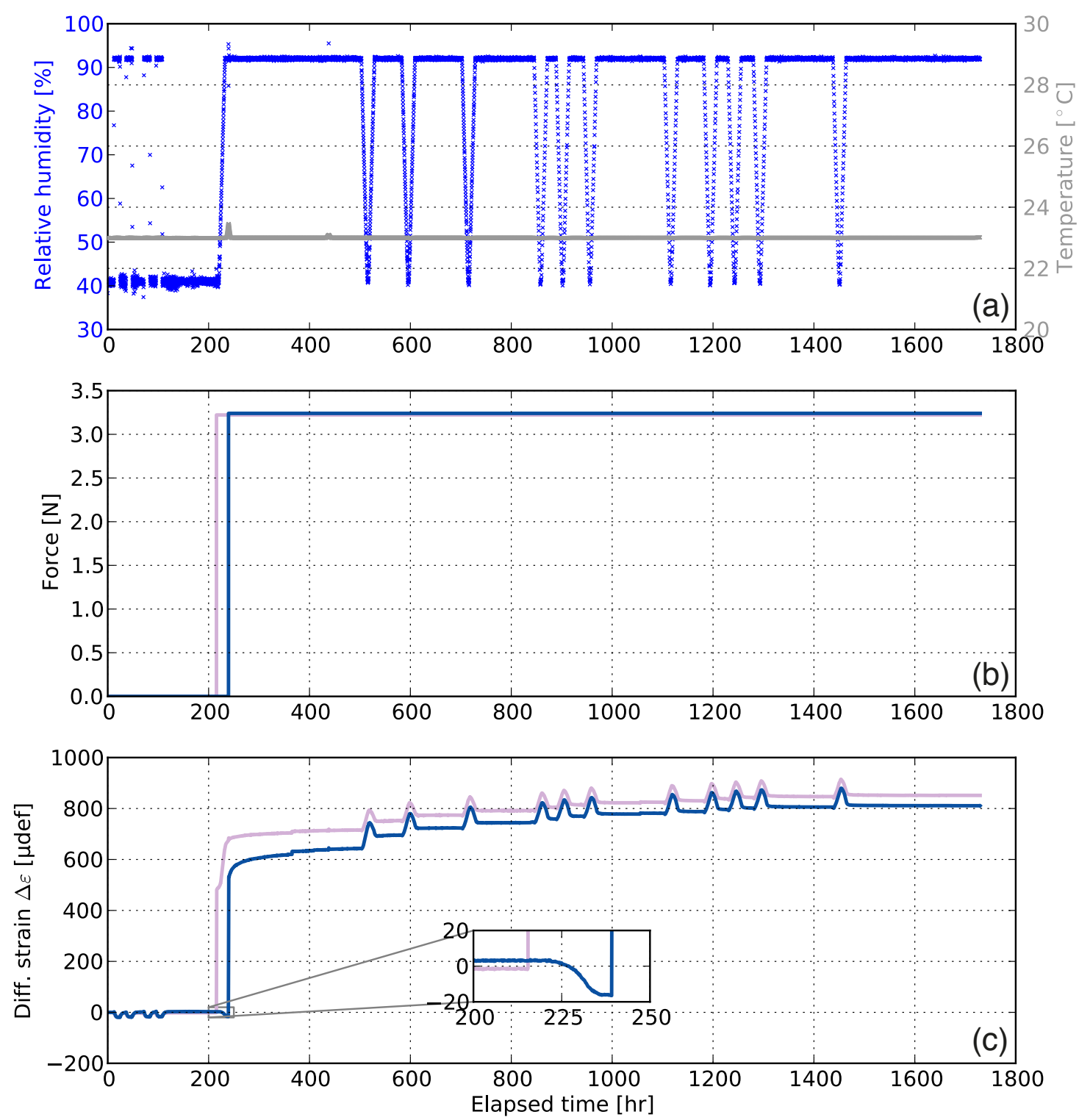

Fig 4 : Overview of the experimental data: (a) hygrothermal environment $\left({ }^{\cdots \cdots} \mathrm{RH}[\%]\right.$, - Temperature $\left.\left[{ }^{\circ} \mathrm{C}\right]\right)$, (b): force $[\mathrm{N}],(\mathrm{c})$ : differential strain $[\mu \varepsilon]$ vs. elapsed time $[\mathrm{h}]$. Means of six specimens for each set dry-loaded set --- and wet-loaded set --- in (b) and (c) representations. Indications of differential strain induced by mechanical loading $\delta \varepsilon(\mathrm{t})=\Delta \varepsilon(\mathrm{t})-\Delta \varepsilon\left(\mathrm{t}_{0}{ }^{-}\right)$.

The relevant parameter for the analysis of mechanosorption is the $\mathrm{MC}$ of the specimens. Figure 5a shows the MC estimate based on the correlation shown in Fig. 3b. The slight drop observed during the constant $\mathrm{RH}$ phases can be explained by the transient expansion observed during changes of relative humidity (Hunt 1990). Figure 5b illustrates that the nominal stress, calculated according to equation (2), drops by $4 \%$ from the dry to wet condition. Higher levels of 
nominal stress are retained temporarily during the humidity cycles. Thus such a test cannot be strictly considered as creep, which theoretically requires a constant stress. The variation is, however, small enough to allow the calculation of a compliance by dividing the differential strain by the nominal stress. The time-dependent compliance $J$ for each loaded specimen is finally calculated as:

$$
J=\frac{\Delta \varepsilon-\Delta \varepsilon^{0}}{\sigma}
$$

where $\sigma$ is calculated from equation (2), $\Delta \varepsilon$ the differential strain induced by the stress and $\Delta \varepsilon^{0}$ the average of differential strain during the 10 min preceding loading at time $t_{0}$. Figure $5 \mathrm{c}$ shows that, as expected, the initial compliance is much higher for the wet-loaded set than for the dry-loaded set. During the first wetting, the dry-loaded set creeps markedly and remains above that of the wetloaded set during the entire test. As shown in Figure 5c, after the last cycle, both curves are almost superimposed. This result suggests that the response of wood to repeated moisture cycles does not depend, after a sufficient number of cycles, on the humidity condition at initial loading.

Within each set, the specimens gave very close results: the StD of the difference in compliance, during the whole loaded period, was $0.005 \mathrm{GPa}^{-1}$ for each sets.
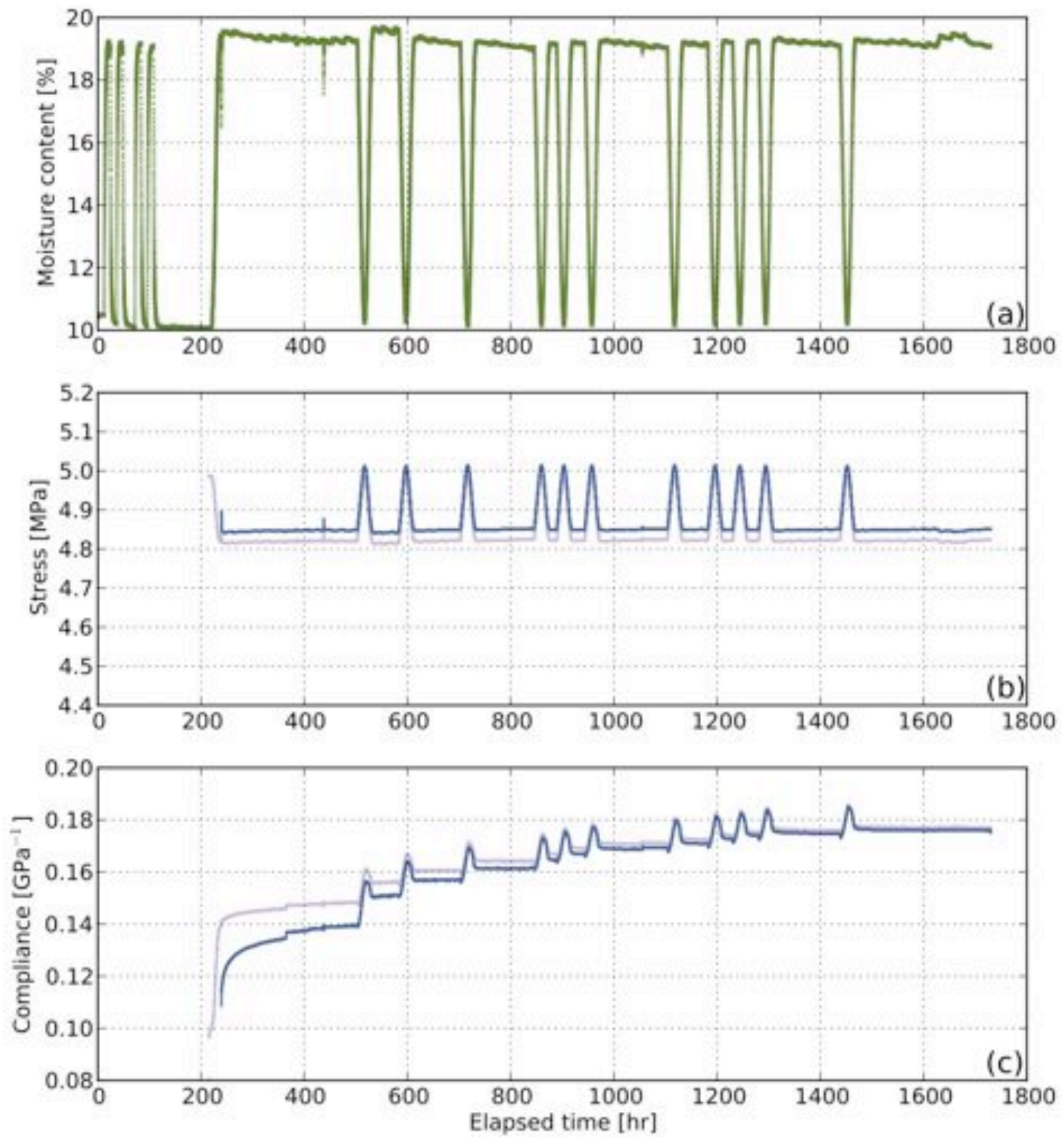

Figure 5: Time evolution of adapted data: (a) moisture content calculated from mean strain of specimens; 
(b) nominal stress $\sigma$, (c) compliance $J$ (— dry-loaded set, — wet-loaded set)

\section{Creep trajectories relative to estimated moisture content}

Figure 6 shows the compliance as a function of the estimated MC. These creep trajectories, which eliminate time, allow discussion of the applicability of the hygroviscoelastic constant concept. The wet-loaded set exhibits a rather typical mechanosorptive response. After the initial wet creep, each drying-wetting cycle induced a significant compliance increase. The approach toward a creep limit is clearly visible.

In the dry-loaded set, the initial wetting period has produced a considerable creep, and the first cycle has a significant effect although smaller than for the wet-loaded set. Then the contributions of subsequent cycles are almost identical in both sets. Obviously, the wet-loaded set tends to catch up with the dry-loaded set. This is clearly demonstrated in Figure 7, presenting the relation between the two sets.
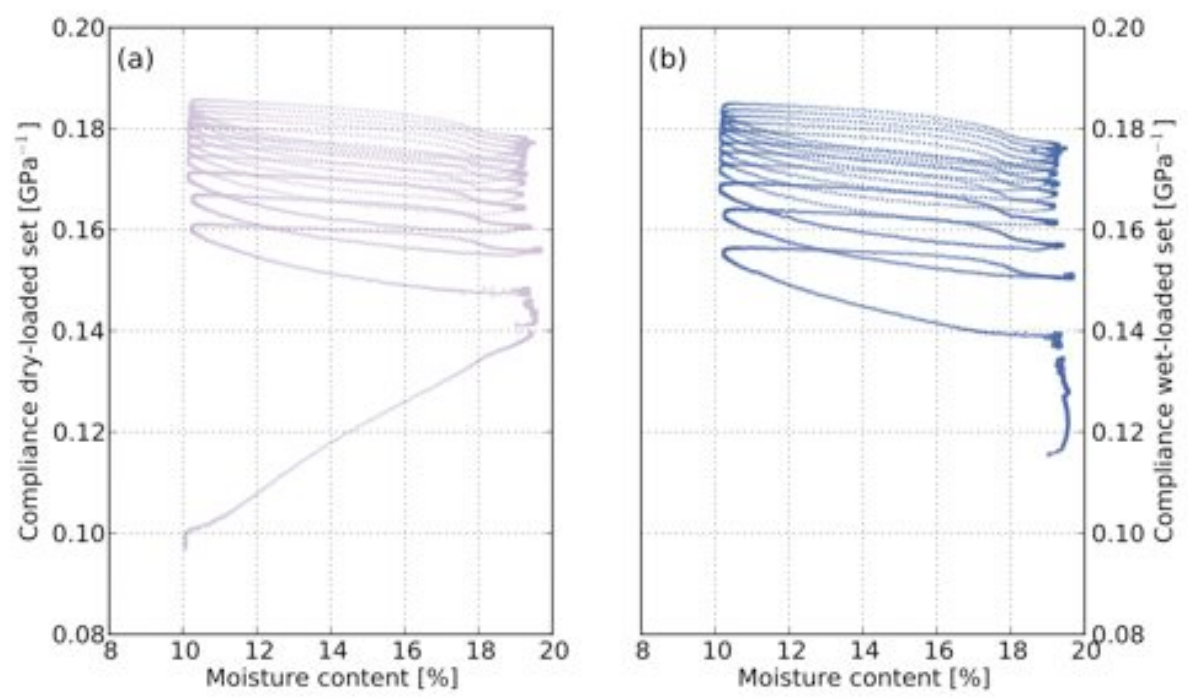

Figure 6: Comparison of compliance trajectories versus estimated moisture content; (left) dry-loaded set followed by a wetting step, then by moisture content cycles and (right) wet-loaded set subjected to the same cycles.

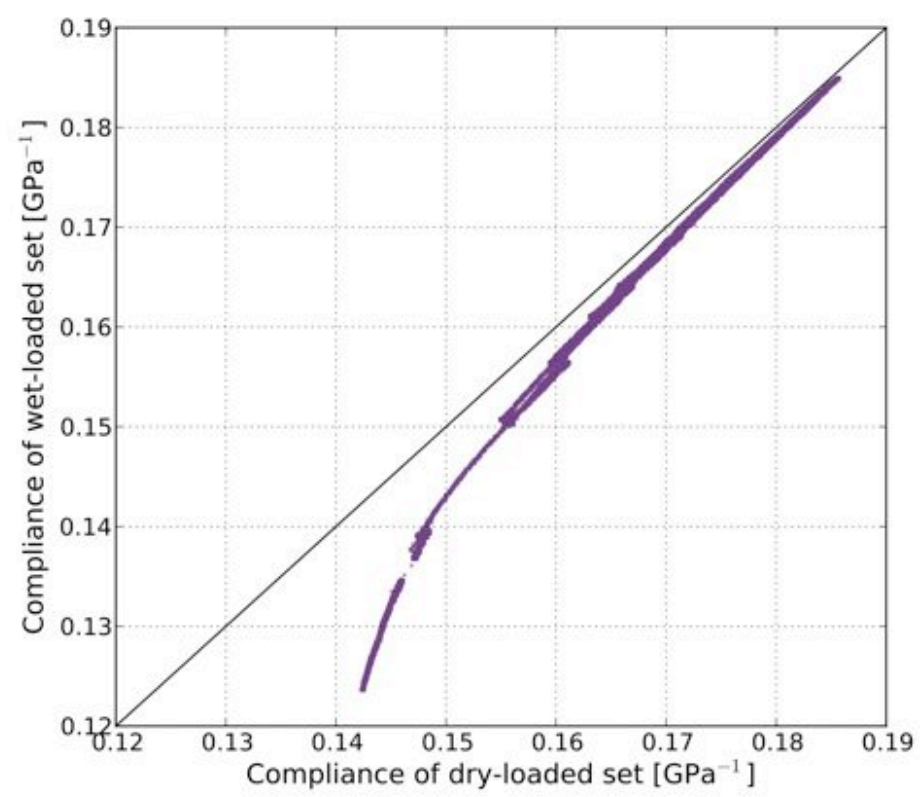

Figure 7: Compliance of wet-loaded set against that of dry-loaded set. 


\section{Discussion}

The construction of creep trajectories was not straightforward in this study because the estimation of MC was based on the average of the mean strain of loaded specimens. This probably accounts, in Figure 6, for the loopy shape of cycle portions and overlapping of successive cycles. However, a precise MC estimation is not required to compare the creep of the two sets.

The first question to address is whether the compliance increase of the dry-loaded set during the first humidifying resulted from viscoelasticity only or involved mechanosorption. In the high humidity region, the mechanosorptive effect is not expected to dominate the "pure" creep that would have been observed at constant humidity. Indeed, through $260 \mathrm{~h}$ of creep in the wet condition, the compliance of the wet-loaded set increased from 0.1135 to $0.1386 \mathrm{GPa}^{-1}$, to compare to the level of $0.1487 \mathrm{GPa}^{-1}$ already attained by the loaded-dry set. A study of the kinetics is required to evaluate how much additional creep the loaded-wet set would have experienced if it had been loaded as long as the loaded-dry set. Based on Hanhijarvi's method (Hanhijarvi and Hunt 1998), a linear extrapolation in logarithm of time since mechanical loading on the last $100 \mathrm{~h}$ shows an estimation of the level of wet-loaded set compliance of $0.1392 \mathrm{GPa}^{-1}$ which leaves for the dryloaded set at least $0.0085 \mathrm{GPa}^{-1}$ of compliance that can be only attributed to mechanosorption. Our results show that adsorption did induce mechanosorptive creep during the first adsorption of the dry-loaded set.

The second question concerns the nature of this mechanosorptive response. During the first wetting, the dry-loaded set was subjected to a typical ++ situation. If the concept of ++ effect applied, an additional creep should have been observed for that set, compared to the wet-loaded set that only experienced "subsequent" adsorption or desorption in the later cycles. The closeness of the response of both sets during the final humidity cycle, demonstrated clearly in Figure 7, suggests very strongly that the marked compliance increase of the dry-loaded set during the first wetting did not correspond to such an additional mechanosorption. It clearly demonstrates that the concept of ++ effect is non-relevant for wood: whatever creep occurred during the first wetting, it was not of a different nature from what happened during later cycles.

These conclusions rely strongly on the quality of the matching. Thanks to the combination method, we have sufficiently reduced the effect of wood variability. Since the possibility of a ++ effect has been ruled out by the preceding argument, the creep of the dry-loaded set during first adsorption can be only be interpreted as + effect. During a moisture cycle under load, as shown in Fig. 1b, pseudo-creep occurs during desorption and pseudo-recovery during adsorption. In addition to this reversible response, which has nothing to do with creep, a net increase of compliance is generally observed between successive cycles. It is usually difficult to separate the respective contributions of desorption and adsorption, as well as that of non-mechanosorptive creep, as we were able to do at the beginning of our creep test. The presented results support the hypothesis that adsorption contributes to mechanosorption, just like desorption. They do not provide guidance on whether both sorption directions contribute equally, as is considered in most models, or by a different amount. However, considering the thermodynamics of the sorption process, even a quantitative difference between the observed effects of adsorption and desorption would not necessarily mean that the mechanisms are intrinsically different.

\section{Conclusions}

Two sets of matched specimens loaded at different humidity levels exhibited the same total response after several humidity cycles under load. The results provided evidence that the first humidifying stage, in a creep test, does not involve the particular phenomenon designated as "++" effect. On the other hand, the marked creep increase during first wetting was partly explained by the increase of viscoelastic compliance, but required also the contribution of mechanosorption.

These findings give strong arguments to simplify our understanding of creep under changing humidity, which could now be reduced to three effects: (1) a single process of mechanosorptive 
creep, regardless of whether it is adsorption or desorption; (2) an added effect of pseudo-creep, based on the differential swelling/shrinkage rates which depend on strain level, and is therefore not creep at all; (3) viscoelastic creep, whose rate increases strongly at high humidities.

These three effects apply in combination, according to humidity and load history. This comparative approach has been supported by this and previous experiments and still needs to be confirmed by further experiment and modelling. The creep data obtained in this study will be also useful for the estimation of long-term wood creep, that involves the complex combination of pure creep and mechanosorption, as well as the quantification of pseudo-creep and progress towards a mechanosorptive creep limit.

\section{Acknowledgements}

The authors gratefully acknowledge the financial support of the Austrian Research Promotion Agency (FFG, project number 815234/12791) and the wood industry partnership Building with Wood within CEI-Bois for supporting this research work within project "MechWood". The "MechWood" research partners are thanked for their cooperation and collaboration in this project. The authors would also like to thank Mr G. Camp (LMGC) and Mr. P. Valorge (LMGC) for technical achievements, Mr G. Calchera (CIRAD) for rupture experiments, and Dr A. Van der Lee (IEM) for X-ray measurements of microfibrillar angle.

\section{References}

Armstrong, L.D. and Christensen, G.N. (1961) Influence of moisture changes on deformation of wood under stress. Nature. 191(4791):869-870

Armstrong, L.D. and Kingston, R.S.T. (1960) Effect of moisture changes on creep in wood. Nature. 185(4716):862-863

Armstrong, L.D. and Kingston, R.S.T. (1962) The effect of moisture content changes on the deformation of wood under stress. Australian J. Appl. Sci. 13(4):257-276

Back, E.L., Salmén, L. and Richardson, G. (1983) Transient effects of moisture sorption on the strength properties of paper and wood-based materials. Svensk Papperstid. 6 - 1983 - 86:61-71

Bazant, Z.P. (1985) Constitutive equation of wood at variable humidity and temperature. Wood Sci. Technol. 19(2):159-177

Boyd, J.D. (1982) An anatomical explanation for visco-elastic and mechano-sorptive creep in wood, and effects of loading rate on strength. In: New perspectives in wood anatomy. Martinus Nijhoff, The Hague. pp. 171-222

Brémaud, I. (2006) Diversité des bois utilisés ou utilisables en facture d'instruments de musique. $\mathrm{PhD}$ Thesis, Université Montpellier 2.

Brémaud, I. (2011, in press) Acoustical properties of wood in string instruments soundboards and tuned idiophones: biological and cultural diversity. To be published (Accepted 25/03/2011) in J. Acoust. Soc. America

Grossman, P.U.A. (1976) Requirements for a model that exhibits mechano-sorptive behaviour. Wood Sci. Technol. 10(3):163-168

Hanhijärvi, A. (1995) Deformation kinetics based rheological model for the time-dependent and moisture induced deformation of wood. Wood Sci. Technol. 29(3):191-199

Hanhijärvi, A. and Hunt, D. (1998) Experimental indication of interaction between viscoelastic and mechano-sorptive creep. Wood Sci. Technol. 32(1):57-70

Herman, M., Dutilleul, P. and Avella-Shaw, T. (1999) Growth rate effects on intra-ring and interring trajectories of microfibril angle in Norway spruce (Picea abies) IAWA journal. Vol.20:

Hoffmeyer, P.a.D., R. (1989) Mechano-sorptive creep mechanism of wood in compressive and bending. Wood Sci. Technol. 23:215-227

Hunt, D.G. (1984) Creep trajectories for beech during moisture changes under load. J. Mater. Sci. 19(5):1456-1467

Hunt, D.G. (1989) Linearity and non-linearity in mechano-sorptive creep of softwood in 
compression and bending. Wood Sci. Technol. 23(4):323-333

Hunt, D. (1990) Longitudinal shrinkage-moisture relations in softwood. J. Materials Sci. 25/8: 3671-3676

Hunt, D.G. and Shelton, C.F. (1987) Stable-state creep limit of softwood. J. Mater. Sci. Letters. 6(3):353-354

Kollmann, F. and Côté, W. (1968) Principles of wood science and technology I. Solid wood Springer-Verlag.

Martensson, A. (1988) Tensile behaviour of hardboard under combined mechanical and moisture loading. Wood Sci. Technol. 22(2):129-142

Mohager, S. and Toratti, T. (1993) Long term bending creep of wood in cycling relative humidity. Wood Sci. Technol. 27:49-59

Mukudai, J. (1983) Evaluation on non-linear viscoelastic bending deflection of wood. Wood Sci. Technol. 17(1):39-54

Muszyński, L., Lagana, R. and Shaler, S.M. (2006) Hygro-mechanical behavior of red spruce in tension parallel to the grain. Wood Fiber Sci., Soc. Wood Sci. Technol. 38: 155-165

Navi, P. and Stanzl-Tschegg S. (2009) Micromechanics of creep and relaxation. A review Holzforschung. 63:186-195

Ranta-Maunus, A. (1975) The viscoelasticity of wood at varying moisture content. Wood Sci. Technol. 9(3):189-205

Salin, J. (1992) Numerical prediction of checking during timber drying and a new mechano-sorptive creep model. Holz Roh- Werkst.. 50:195-200

Yamamoto, H., Okuyama, T., and Yoshida, M. (1993) Method of determining the mean microfibril angle of wood over a wide-range by the improved Cave's method. Mok. Gakk. 39: 375-381 